Vol. 1, No. 4, 2019

Jurnal Terapan Sains \& Teknologi

Fakultas Sains dan Teknologi - Universitas Kanjuruhan Malang

\title{
RANCANG BANGUN ALAT PENYEBAR PAKAN SECARA MAKSIMAL PADA MESIN PEMBERI MAKAN OTOMATIS IKAN LELE
}

\author{
Ahmad Zaelani' ${ }^{1}$, Danang Aditya Nugraha ${ }^{2}$, Anggri Sartika Wiguna ${ }^{3}$ \\ Teknik Informatika, Universitas Kanjuruhan Malang ${ }^{1,2,3}$ \\ zaelaniahmad3027@gmail.com¹, danang.adty@unikama.ac.id ${ }^{2}$, anggrisartika@ unikama.ac.id ${ }^{3}$
}

\begin{abstract}
Abstrak. Teknologi sistem cerdas dapat membantu meringankan pekerjaan dalam menunjang pembudidaya contohnya pembudidaya ikan lele. Dalam perawatan ikan lele perlu adanya proses pemberian pakan ikan. Sehari pemberian pakan dilakukan sebanyak 3 kali yaitu pagi, sore, malam dan penebaran pakan harus diberikan secara merata agar pertumbuhan ikan sama rata. Pada dasarnya pembudidaya ikan lele masih menggunakan cara manual dalam memberikan pakan ikan lele tersebut. Dari hasil penelitian ini membuat sistem dengan kemampuan menebarkan pakan ikan lele secara merata. Sehingga dalam perawatan ikan lele lebih mudah dan menghemat waktu pembudidaya karena pemberian pakan ikan dilakukan secara otomatis dan pertumbuhan ikan lele bisa lebih baik lagi dibandingkan dengan pemberian pakan ikan lele cara manual.
\end{abstract}

Kata Kunci : Arduino Uno, penebar pakan, ikan lele, sample variance, PWM

\section{PENDAHULUAN}

Budidaya ikan air tawar merupakan usaha yang dapat memperoleh keuntungan. Ikan lele merupakan produk unggulan air tawar yang memiliki harga ekonomi lebih tinggi. Ikan lele dipasarkan dalam keadaan hidup maupun mati dan dibekukan dengan menggunakan es balok untuk membuat ikan lele tersebut bisa bertahan satu minggu dalam ke adaan mati. Didaerah Kec. Turen Kab. Malang banyak terdapat pembudidaya - pembudidaya ikan lele. Namun demikian, dari hasil wawancara dengan pembudidaya ikan lele masih terdapat kendala yang dihadapi pembudidaya ikan. Kegiatan memberi pakan ikan yang dilakukan secara manual terkadang mengalami keterlambatan dan tidak sesuai dengan jadwal yang telah ditetapkan, ini dikarenakan adanya pekerjaan lain yang masih dilakukan ataupun lupa. Apabila tetap dibiarkan maka dapat menghambat pertumbuhan ikan lele tersebut. Oleh karena itu perlu dicari solusi bagaimana caranya para pembudidaya bisa memberi makan ikan lele yang dibudidayakan dengan teratur dan tepat waktu tanpa harus mengganggu aktivitas pembudidaya sehari hari.

Berdasarkan gambaran diatas, maka perlu dibuat suatu sistem kontrol berbasis mikrokontroler yang mampu melaksanakan tugas pemberian pakan ikan yang bekerja secara otomatis. Dengan adanya perangkat ini para pembudidaya ikan diharapkan tercapai efisiensi dan efektifitas dalam kegiatan pembudidayaan ikan tersebut.

Berdasarkan pemaparan latar belakang diatas, maka salah satu upaya dalam menebarkan pakan secara maksimal di kolam ikan lele agar pertumbuhan ikan lele menjadi lebih baik dan menghemat waktu pembudidaya untuk kesibukan lainnya maka di buatlah "PROTOTYPE ALAT PENEBAR PAKAN SECARA MAKSIMAL PADA MESIN PEMBERI MAKAN OTOMATIS IKAN LELE" di harapakan dalam penelitian ini dapat menyelesaikan permasalahan pemberian pakan ikan lele yang dilakukan secara manual menjadi otomatis. 


\section{Representatif pengetahuan}

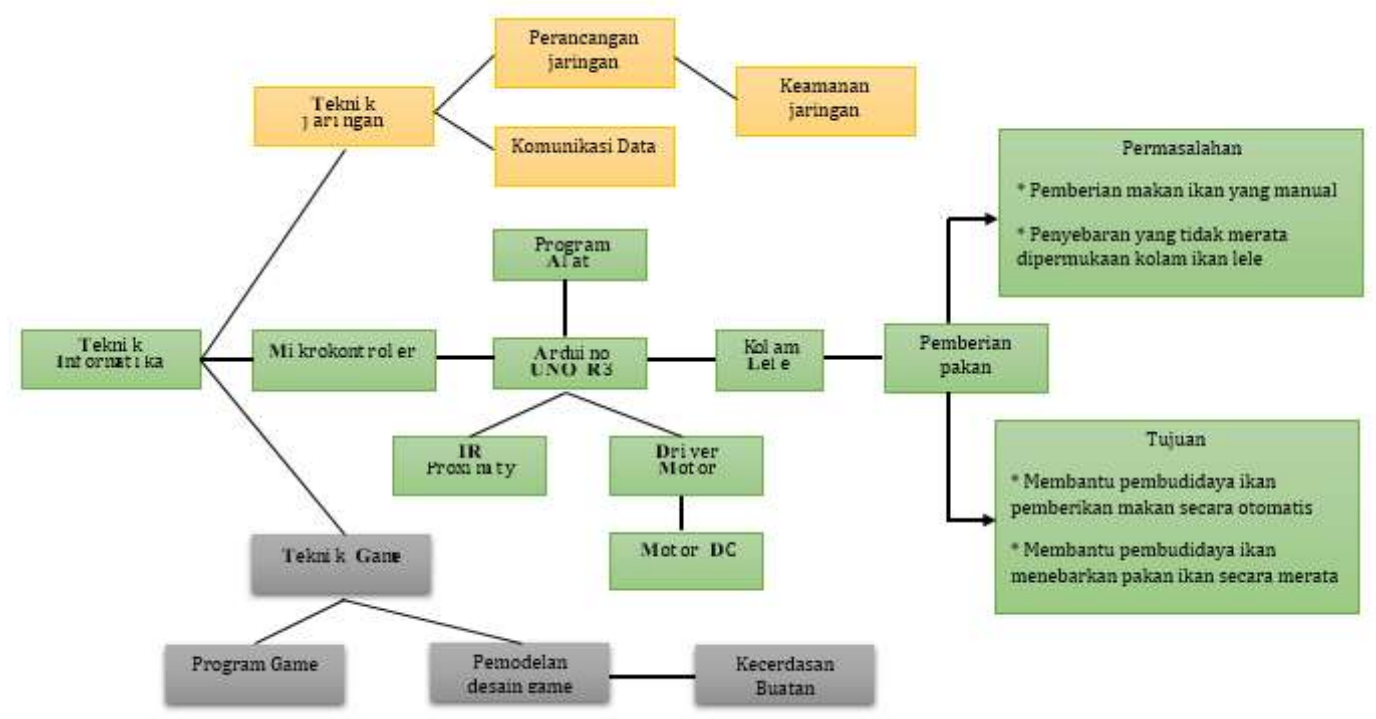

Gambar 1. Representatif pengetahuan

\section{Prototipe}

Prototipe adalah pengembangan suatu model software sederhana yang mengijinkan pengguna memiliki gambaran dasar program, disini juga bisa penjadwalan dalam melakukan pengujian. Prototype juga memberikan fasilitas bagi pengembang dan pemakai untuk saling berinteraksi dalam suatu proses pembuatan, sehingga pengembang dapat memodel sesuai perangkat yang ingin dibuat sesuai kebutuhan.

\section{Arduino UNO R3}

Arduino uno R3 adalah papan mikrokontroler berbasis Atmega328. Arduino uno memiki 14 kaki digital input dan output dimana 6 kaki digital dapat digunakan sebagai sinyal PMW (pulse width modulation ). Sinyal PMW untuk mengatur kecepatan perputaran motor yang digunakan. Arduino uno memiliki 6 kaki analog input, kristal osilator denagn kecepatan $16 \mathrm{MHz}$, koneksi USB, jack listrik, kaki header dari ICSP dan tombol reset yang mengulang sebuah program yang akan dijalankan. Bord ini bisa dihubungkan ke komputer untuk memprogram baru atau yang lama, sehingga bisa tersambung ke internet dengan kabel USB atau daya eksternal lainya dengan daya ac maupun de dan baterai.

\section{Rumus varian sample dan standart deviation}

Varians adalah ukuran seberapa tersebarnya data. Varians yang rendah menandakan data yang berkelompok dekat satu sama lain. Varians yang tinggi menandakan data yang lebih tersebar. Konsep ini memiliki banyak kegunaan di dalam statistik. Misalnya, membandingkan varians dari dua kelompok data (seperti hasil dari pasien laki-laki dan perempuan) adalah salah satu cara untuk menguji apakah sebuah variabel memiliki efek yang dapat diamati. Varians juga berguna saat membuat model statistik, karena varians yang rendah menandakan data yang over-fitting.

Sample variance $\left(\mathbf{S}^{2}\right)$

$$
\begin{gathered}
S^{2}=\frac{\Sigma\left(x_{i}-\tilde{X}\right) 2}{n-1} \\
S^{2}=\text { Variance }
\end{gathered}
$$


$\mathbf{X}_{\mathrm{i}}=$ Tern in data set

$\dot{\mathrm{X}}=$ Sample mean

$\sum=$ Sum

$\mathbf{n}=$ Simple size

Tabel 1 Rumus variance sample dan standart deviation

\begin{tabular}{c|c}
\hline Rumus variance sample & Rumus standart daviation \\
\hline$S^{2}=\frac{\sum\left(X_{i}-\dot{\mathrm{X}}\right)^{2}}{n-1}$ & $S^{2}=\sqrt{\frac{\sum\left(X_{i}-\dot{\mathrm{X}}\right)^{2}}{n-1}}$ \\
\hline
\end{tabular}

Pahami varians sampel dan standar deviasi, di dalam rumus ini ada pengkuadratan, varians diukur dalam unit kuadrat dari data asli. Hal ini membuat kita sulit untuk memahami data secara intuitif. Oleh karena itu ada baiknya kita menggunakan standar deviasi. Anda tidak perlu repot-repot, karena standar deviasi didefinisikan sebagai akar kuadrat dari varians. Oleh karena itu varians sampel dituliskan dengan $\mathrm{S}^{2}$, dan standar deviasi sampel dengan $\mathrm{S}$.

\section{Rumus PWM (Pulse Width Modulation )}

Pulse Width Modulation (PWM) secara umum adalah sebuah cara memanipulasi lebar sinyal yang dinyatakan dengan pulsa dalam suatu perioda, untuk mendapatkan tegangan rata-rata yang berbeda. Aplikasi PWM berbasis mikrokontroler biasanya berupa pengendalian kecepatan motor DC, pengendalian motor servo, pengaturan nyala terang LED dan lain sebagainya.

Sinyal PWM pada umumnya memiliki amplitudo dan frekuensi dasar yang tetap, namun memiliki lebar pulsa yang bervariasi. Lebar Pulsa PWM berbanding lurus dengan amplitudo sinyal asli yang belum termodulasi. Artinya, Sinyal PWM memiliki frekuensi gelombang yang tetap namun duty cycle bervariasi (antara $0 \%$ hingga $100 \%$ ).

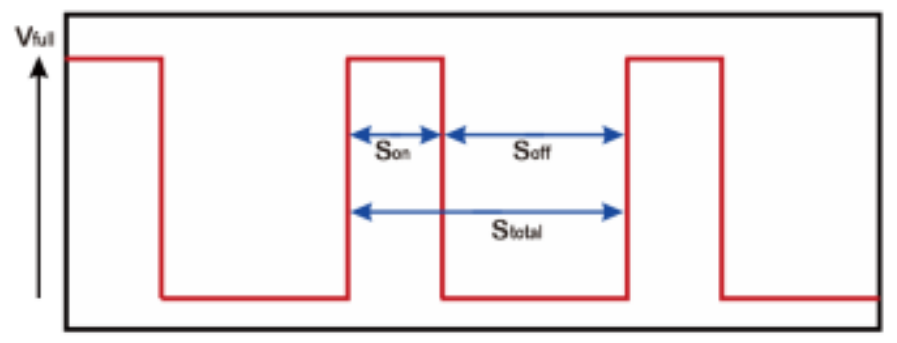

Gambar 2. Rumus PWM (Pulsa Widht Modulation)

Rumus PWM (Pulse Width Modulation)

Penjelasan:

$$
D=\frac{S_{\text {on }}}{\left(S_{\text {on }}+S_{\text {off }}\right.}=\frac{S_{\text {on }}}{S_{\text {total }}} \text { Sehigga: } V_{\text {out }}=\frac{S_{\text {on }}}{S_{\text {total }}} x V_{\text {in }}
$$

$\mathrm{D}=$ Duty Cycle yaitu lamanya pulsa hight dalam satu perioda

$\mathrm{S}_{\mathrm{on}}=$ sinyal Hight

$S_{\text {off }}=$ sinyal Low

$\mathrm{S}_{\text {total }}=$ sinyal total dalam satu perioda

$\mathrm{V}_{\text {out }}=$ tegangan keluaran

$\mathrm{V}_{\text {in }}=$ Tegangan masukan

Resolusi adalah jumlah variasi perubahan nilai dalam PWM tersebut. Misalkan suatu PWM memiliki resolusi 8 bit berarti PWM ini memiliki variasi perubahan nilai sebanyak $28=$ 256 variasi mulai dari $0-255$ perubahan nilai yang mewakili duty cycle $0-100 \%$ dari keluaran PWM tersebut. 


\section{METODE PENELITIAN}

\section{Tempat dan waktu penelitian}

Penelitian "Prototipe alat penebar pakan secara maxsimal pada mesin pemberi makan otomatis ikan lele menggunakan Arduino UNO" penelitian ini dilaksanakan di dua tempat yakni dikontrakan dan Turen.

Untuk menunjang Pembuatan Prototipe alat penebar pakan secara maxsimal pada mesin pemberi makan otomatis ikan lele, diperlukan beberapa fasilitas untuk pendukung kinerja pembuatan alat yang akan dijalankan. Antara lain fasilitas yang akan dibutuhkan sebagai pendukung pembuatan alat supaya berjalan dengan sempurna adalah perangkat keras dan perangkat lunak.

\section{Kebutuhan perangkat keras}

Adapun komponen perangkat keras yang dibutuhkan pembuatan Prototipe alat penebar pakan secara maxsimal pada mesin pemberi makan otomatis ikan lele ini adalah sebagai berikut:

1. $\mathrm{PC}$ atau laptop, digunakan untuk membuat program dan menjalankan.

2. Arduino Uno R3 sebagai pusat kendali utama dari semua komponen.

3. Motor DC digunakan sebagai motor penggerak kipas penebar pakan.

4. Modul Motor Driver L298N sebagai penetralisir motor De sesuai perintah yang di suruh dan pengatur alur arus lisrtik.

5. LCD. Untuk menampilkan hasil proses yang di program

6. Sensor Proxsimity

7. Power Supply.

8. Sorder.

9. Timah.

10. Adaptor 9v.

11. Kabel USB.

12. Kabel LAN.

\section{Kebutuhan perangkat lunak}

Adapun perangkat lunak yang digunakan untuk implementasi pembuatan perangkat ini antara lain sebagai berikut :

1. Sistem operasi Microsoft windows 8.1.

2. Software Arduino uno Intergrated Development Environment (IDE) Arduino Uno 1.8.8 untuk menguploud program dari PC ke Arduino Uno.

3. Bahasa $\mathrm{C} / \mathrm{C}++$ sebagai bahasa pemograman Arduino Uno.

\section{Rancangan Sistem}

Rancangan sistem dari alat penebar pakan ikan lele, diawali dengan inputan dideteksi dengan sensor Proximity. Dari inputan yang dihasilkan tersebut, kemudian akan diproses oleh mikrokontroler arduino uno, mikrokontroler ini memproses semua inputan yang dihasilkan oleh sensor proximity tersebut. Sedangkan proses arduino uno menghasilkan output yakni berupa tegangan dinamo yang berputar sesuai program yang sudah di masukan ke dalam mikrokontroler arduino uno. 


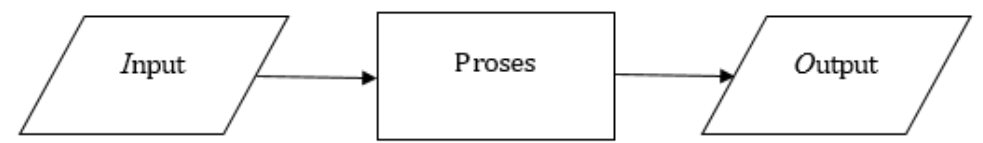

Gambar 3. Perancangan sistem penebar pakan ikan lele

Diagram Blok

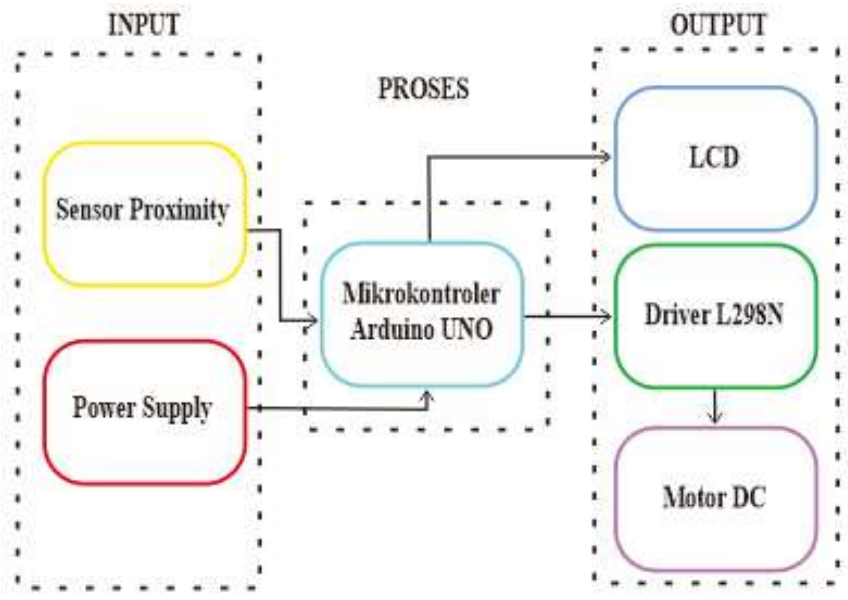

Gambar 4. diagram blok alat penebar pakan ikan lele

Berdasarkan blok diagram diatas, terdapat fungsi masing-masing yang ada pada alat-alat dan komponen-komponen tersebut adalah sebagai berikut :

1. Sensor Proximity berfungsi sebagai pendeteksi pakan yang lewat di atas permukaan sensor lalu diproses ke mikrokontroler arduino.

2. Inisialisasi berfungsi sebagai pengecekan alat ini

3. Power supply 9V berfungsi sebagai menormalkan arus yang masuk ke mikrokontroler Arduino.

4. LCD berfungsi sebagai output dari sensor Proximity mendeteksi pakan yang lewat diatas lalu dikirim ke Arduino maka LCD akan membaca atau memberikan informasi yang terdeteksi oleh sensor proximity tersebut.

5. Driver L298N berfungsi sebagai driver untuk mengatur laju motor dc dan memerintah kan sesuai program yang dibuat di dalam mikrokontroler arduino uno.

6. Motor Dc berfungsi sebagai penggerak kipas penebar pakan yang akan di sebarkan secara maksimal ke kolam ikan lele

Berikut adalah rangakain keseluruhan dari system alat penebar pakan ikan lele :

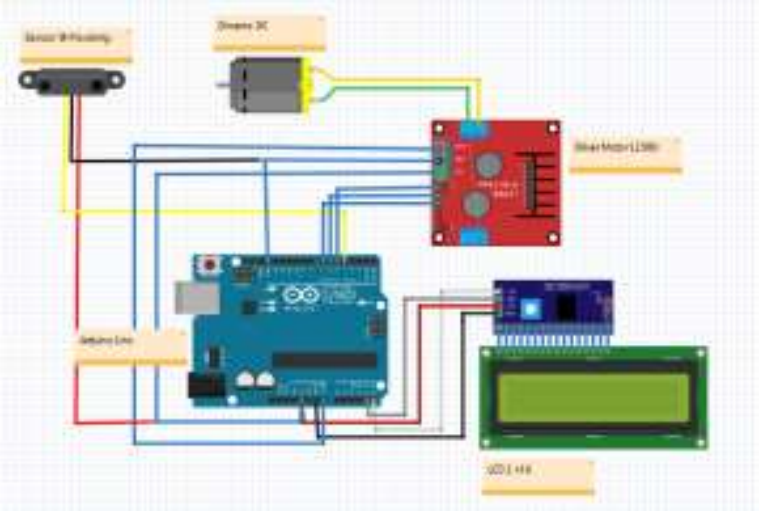

Gambar 5. Rangkaian keseluruhan alat penebar pakan ikan lele 


\section{RAINSTEKK \\ Jurnal Terapan Sains \& Teknologi}

Vol. 1, No. 4, 2019

Fakultas Sains dan Teknologi - Universitas Kanjuruhan Malang

Keterangan dari rangkaian keseluruan gambar diatas sebagai berikut :

1. Sensor IR Proximity adalah sensor yang berfungsi sebagai pedeteksi pakan ikan yang melewati sensor tersebut, gerakan pakan yang melewati sensor ini sebagai inputan.

2. Arduino uno, adalah sebagai pusat dari proses yang utama dari sistem alat penebar pakan ikan otomatis ini.

3. LCD dengan menggunakan $12 \mathrm{c}$ yang berfungsi sebagai interfec penampilan perintah yang ada program, penampilan keadaan penebar pakan dalam keadaan On atau Off.

4. Motor Driver L298 berfungsi sebagai motor penggerak motor DC untuk menggerakan Dinamo yang berfungsi untuk menebarkan pakan ikan keatas permukaan kolam secara merata dan juga sebagai output dari sistem ini.

\section{Flowchart}

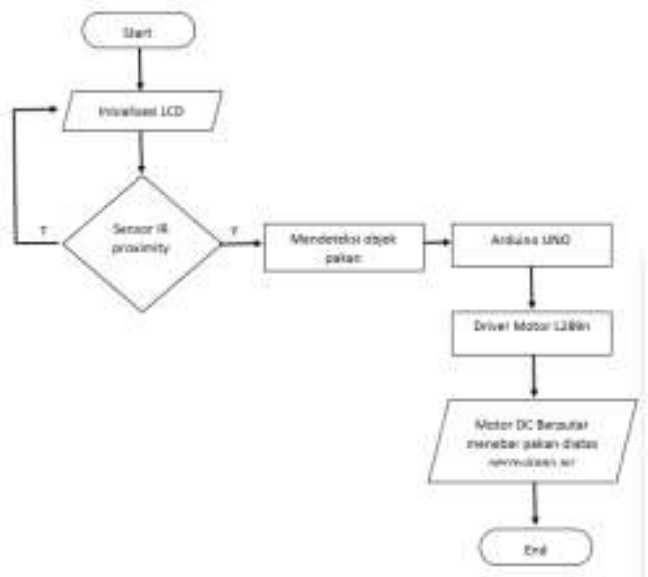

Gambar 6. flowchart alat penebar pakan ikan lele

\section{Gambar Perancangan Desain alat penebar pakan ikan lele.}

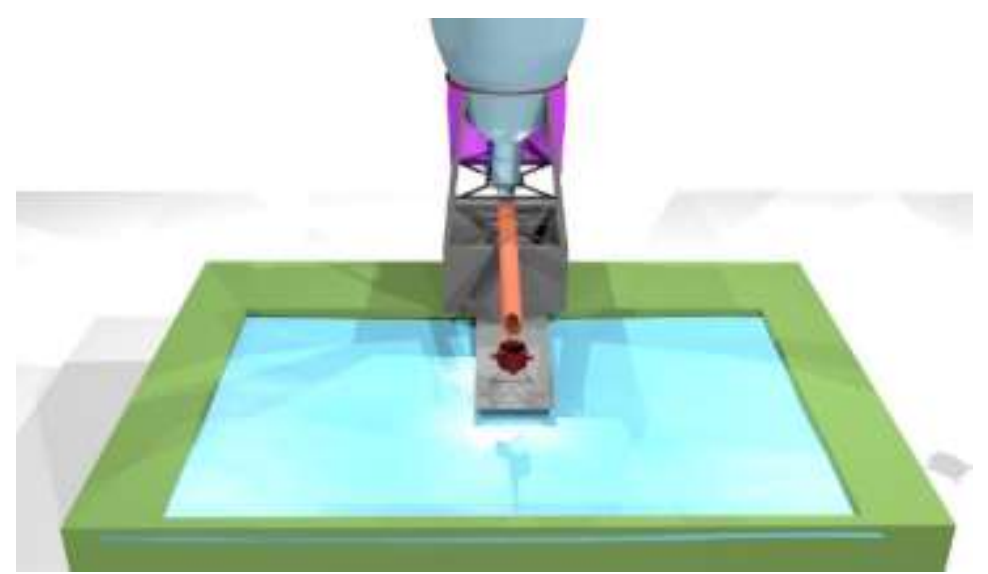

Gambar 7. Perancangan Desain alat penebar pakan ikan lele

Keterangan gambar di atas :

1. Pipa paralon untuk lewat pakan ikan lele dari tandon ke kolam

2. Sensor IR Proximity untuk mendeteksi adanya pakan atau tidak

3. Dynamo untuk menggerakan kipas dan menebarkan pakan di atas permukaan kolam

4. LCD untuk memberikan informasi penyebaran pakan. 
Perhitungan PWM

1. Perhitungan 160 PWM

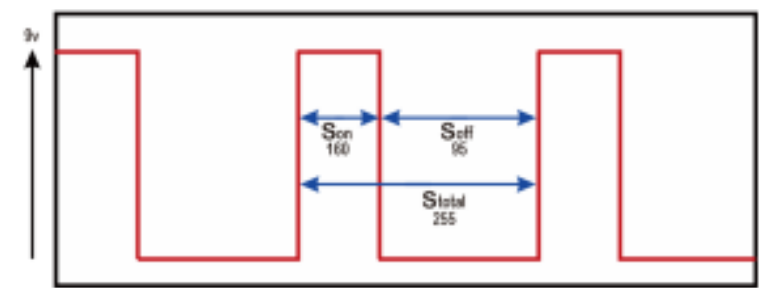

Gambar 8. Perhitungan PWM 160

$$
\begin{gathered}
D=\frac{S_{\text {on }}}{\left(S_{\text {on }}+S_{\text {off }}\right.}=\frac{S_{\text {on }}}{S_{\text {total }}} \text { Sehigga: } V_{\text {out }}=\frac{S_{\text {on }}}{S_{\text {total }}} \times V_{\text {in }} \\
D=\frac{160}{(160+95)}=\frac{160}{255} \text { Sehigga: } V_{\text {out }}=0,6 \times 9=5,4 \text { volt }
\end{gathered}
$$

\section{Perhitungan 140 PWM}

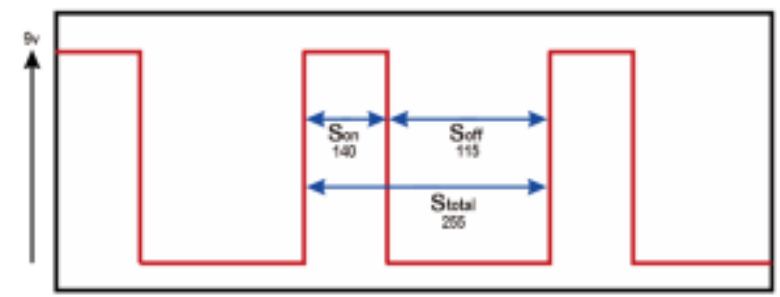

Gambar 9. Perhitungan PWM 140

$$
\begin{gathered}
D=\frac{S_{\text {on }}}{\left(S_{\text {on }}+S_{\text {off }}\right.}=\frac{S_{\text {on }}}{S_{\text {total }}} \text { Sehigga: }: V_{\text {out }}=\frac{S_{\text {on }}}{S_{\text {total }}} \times V_{\text {in }} \\
D=\frac{140}{(140+115)}=\frac{140}{255} \text { Sehigga: } V_{\text {out }}=0,5 \times 9=4,5 \text { volt }
\end{gathered}
$$

3. Perhitungan 120 PWM

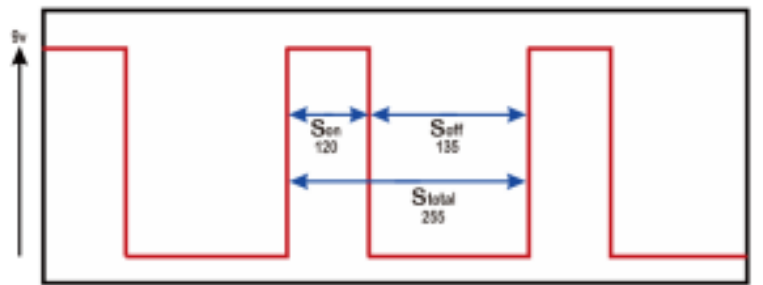

Gambar 10. Perhitungan PWM 120

$$
\begin{gathered}
D=\frac{S_{\text {on }}}{\left(S_{\text {on }}+S_{\text {off }}\right.}=\frac{S_{\text {on }}}{S_{\text {total }}} \text { Sehigga: } V_{\text {out }}=\frac{S_{\text {on }}}{S_{\text {total }}} \times V_{\text {in }} \\
D=\frac{120}{(120+135)}=\frac{120}{255} \text { Sehigga: } V_{\text {out }}=0,4 \times 9=3,6 \text { volt }
\end{gathered}
$$




\section{RAIINSTEK \\ Jurnal Terapan Sains \& Teknologi}

Vol. 1, No. 4, 2019

Fakultas Sains dan Teknologi - Universitas Kanjuruhan Malang

\subsection{Perhitungan Sample Variance dan Sample Standart Deviation}

Dari pengujian ketiga sirip 2, 3, dan 4 dilakukan masing-masing 3 kali percobaan, dan didapatkan hasil yang berbeda-beda, terlihat pada tabel sebagai berikut :

Tabel 2. Perhitungan Sample Variance dan Sample Standart Deviation Percobaan 1

\begin{tabular}{c|c|l}
\hline Percobaan 1 & Sample Variance & Sample Standart Deviation \\
\hline Sirip 2 & $S^{2}=\frac{\sum\left(X_{i}-\dot{X}\right)^{2}}{n-1}$ & $S^{2}=\frac{\sum\left(X_{i}-\dot{X}\right)^{2}}{n-1}$ \\
& $S^{2}=15,00694$ & $S^{2}=\sqrt{15,00694}$ \\
Sirip 3 & $S^{2}=\frac{\sum\left(X_{i}-\dot{X}\right)^{2}}{n-1}$ & $S^{2}=\frac{\sum\left(X_{i}-\dot{X}\right)^{2}}{n-1}$ \\
& $S^{2}=26,37277$ & $S^{2}=\sqrt{26,37277}$ \\
& $S^{2}=\frac{\sum\left(X_{i}-\dot{X}\right)^{2}}{n-1}$ & $S^{2}=\frac{\sum\left(X_{i}-\dot{X}\right)^{2}}{n-1}$ \\
\hline \multirow{2}{*}{ Sirip 4 } & $S^{2}=45,41171$ & $S^{2}=\sqrt{45,41171}$ \\
& & $=6,738821$ \\
\hline
\end{tabular}

Tabel 3. Perhitungan Sample Variance dan Sample Standart Deviation Percobaan 2

\begin{tabular}{c|c|c}
\hline Percobaan 2 & Sample Variance & Sample Standart Deviation \\
\hline Sirip 2 & $S^{2}=\frac{\sum\left(X_{i}-\dot{X}\right)^{2}}{n-1}$ & $S^{2}=\frac{\sum\left(X_{i}-\dot{X}\right)^{2}}{n-1}$ \\
& $S^{2}=17,93552$ & $S^{2}=\sqrt{17,93552}$ \\
& $S^{2}=\frac{\sum\left(X_{i}-\dot{X}\right)^{2}}{n-1}$ & $S^{2}=\frac{\sum\left(X_{i}-\dot{X}\right)^{2}}{n-1}$ \\
Sirip 3 & $S^{2}=49,44444$ & $S^{2}=\sqrt{49,44444}$ \\
& $S^{2}=\frac{\sum\left(X_{i}-\dot{X}\right)^{2}}{n-1}$ & $S^{2}=\frac{\sum\left(X_{i}-\dot{X}\right)^{2}}{n-1}$ \\
\hline Sirip 4 & $S^{2}=25,01265$ & $S^{2}=\sqrt{25,01265}$ \\
& & $=5,001265$ \\
\hline
\end{tabular}


Tabel 4. Perhitungan Sample Variance dan Sample Standart Deviation Percobaan 3

\begin{tabular}{|c|c|c|}
\hline Percobaan 3 & Sanple Variance & Saneple Standart Deviation \\
\hline Sirip 2 & $\begin{array}{l}s^{2}=\frac{\Sigma x_{i}-\mathrm{X}^{2}}{n-1} \\
s^{2}=17.9561\end{array}$ & $\begin{array}{l}s^{2}=\frac{\sum\left(X_{4}-x\right)^{2}}{n-1} \\
s^{2}=\sqrt{17.9561} \\
=4.237464\end{array}$ \\
\hline Sarip 3 & $\begin{array}{l}s^{2}=\frac{\sqrt[D x_{i}-\dot{x} j^{2}]{n-1}}{s^{2}}=26.83234\end{array}$ & $\begin{array}{l}s^{2}=\frac{\sum\left(x_{1}-x\right)^{2}}{n-1} \\
s^{2}=\sqrt{26.83234} \\
=5.179994\end{array}$ \\
\hline Sirip 4 & $\begin{array}{l}s^{2}=\frac{\left.\sum X X_{i}-X\right)^{2}}{n-1} \\
s^{2}=60.43031\end{array}$ & $\begin{array}{l}s^{2}=\frac{\sum\left(X_{1}-x\right)^{2}}{n-1} \\
s^{2}=\sqrt{60,43031} \\
=6.358483\end{array}$ \\
\hline
\end{tabular}

Dari hasil perhitungan diatas, percobaan sirip lubang 2, 3, dan 4 nilai yang paling kecil didapatkan pada sirip yang menggunakan 2 lubang. Maka dapat disimpulkan bahwa sirip yang paling merata dalam menebarkan pakan lele adalah sirip lubang 2.

\section{PENUTUP}

\section{Kesimpulan}

Dalam pembuatan skripsi ini telah di buat alat penyebar pakan secara maksimal pada alat pemberi makan otomatis ikan lele. Dari pembuatan alat tersebut diambil kesimpulan sebagai berikut :

1. Konsep simulasi 3D yang dibuat berupa sirip-sirip yang memiliki lubang 2, 3, 4, dan dibuat menggunakan Arduino Uno sebagai pengolah data dari sensor IR Proximity yang berfungsi mendeteksi pakan yang melintasi sensor lalu menggerakan dinamo sebagai penggerak sirip-sirip tersebut.

2. Berdasarkan dari pengujian masing-masing sirip yang dilakukan pada prototipe alat ini, sirip yang menggunakan lubang 2 yang lebih efisien dalam penebaran pakan ikan lele ke permukaan kolam

Saran

Dari perancangan alat penyebar pakan secara maksimal pada alat pemberi pakan otomatis ikan lele diharapkan dapat menjadi dasar penelitian lebih lanjut. Saran yang dapat diberikan untuk mengembangkan lebih baik adalah sebagai berikut :

1. Menambah indikator untuk memberikan informasi secara online apakah pakan ikan sudah tersebar atau belum.

2. Karena pembuatan sistem alat ini menggunakan arduino uno bisa di kembangkan lagi dengan menggunakan alat yang memiliki kemampuan lebih seperti rasbery atau mikrokontroler yang lain.

\section{DAFTAR PUSTAKA}

Saragih, A. R. (2016). Rancang Bangun Perangkat Pemberi Pakan Ikan Otomatis Pada Kolam Pembenihan Ikan Berbasis Arduino. Artikel E-Journal. Retrieved from 
http://jurnal.umrah.ac.id/wp-content/uploads/gravity_forms/1ec61c9cb232a03a96d0947 c6478e525e/2016/08/e-Jurnal-Astriani-Romaria-Saragih.pdf

Weku, H. s. (2015). Rancang Bangun Alat Pemberi Pakan Ikan Otomatis Berbasis Mikrokontroler. Teknik Elektro Dan Komputer, 5(Pakan Ikan Otomatis), 54-64.

Akhir, T., \& Syahlanda, R. (2017). Rancang bangun alat pemberi makan kucing berbasis mikrokontroler, 1-62.

Ariyanto, E. Y., Aman, M., \& Rochmad, C. D. (2013). Perancangan dan Pembuatan Sistem Penebar Pakan Ikan Jenis Pasta Otomatis Berbasis Mikrokontroler AT89S51, 1-3.

Helda Yenni, B. (2016). Perangkat Pemberi Pakan Otomatis pada Kolam Budidaya. Ilmiah Media Processor, 11(2), 171-181.

Santoso, B., Arifianto, A.B.(2014). Sistem pengganti air berdasarkan kekeruhan dan pemberi pakanvikan pada akuarium air tawar secara otomatis berbasis mikrokontroler atmega 16.Jurnal Ilmiah Teknologi dan Informasi ASIA, 8(2),33-48

Sari, K.,Suhery, C., Arman, Y. (2015). Implementasi sistem pakan ikan menggunakan buzzer dan aplikasi berbasis mikrokontroler. Jurnal Coding Sistem Komputer Untan. 03(2),111-122

Arduino. "Website Opensource Arduino "https://www.arduino.cc/ Kadir, abdul. (2015).From zero to a Pro Arduino Yogyakarta: ANDI. 